\title{
Potential impact of dairy yeasts on the typical flavour of traditional ewes'
} and goats' cheeses

Beatriz Padilla ${ }^{a}$, Carmela Belloch ${ }^{a}$, José Javier López-Díez ${ }^{a}$, Mónica Flores ${ }^{b}$ and Paloma Manzanares a ,

aDepartamento de Biotecnología de Alimentos Instituto de Agroquímica y Tecnología de Alimentos, Consejo Superior de Investigaciones Científicas (CSIC), Paterna, Valencia, Spain.

${ }^{\mathrm{b} D e p a r t a m e n t o}$ de Ciencia de los Alimentos, Instituto de Agroquímica y Tecnología de Alimentos, Consejo Superior de Investigaciones Científicas (CSIC), Paterna, Valencia, Spain.

*Corresponding author: Tel.: 34-96-3900022; Fax: 34-96-3636301; e-mail address: pmanz@iata.csic.es

9


26 The contribution of Debaryomyces hansenii, Kluyveromyces lactis and

27 Kluyveromyces marxianus strains to the typical flavour of traditional ewes' and 28 goats' cheeses was assessed. Fourteen yeast strains were grown in liquid 29 medium mimicking cheese composition and volatile compounds were identified

30 by GC-MS. Yeasts were able to produce key volatile compounds characteristic 31 of the cheeses from which they were isolated. Inter-species and inter-strain

32 variations were observed. Under the conditions tested $D$. hansenii produced the 33 lowest levels of volatile compounds, with large intra-strain variations.

34 Kluyveromyces strains primarily produced esters and alcohols. K. marxianus 35 strains were associated with the production of acids, ethyl decanoate, 136 propanol and benzaldehyde, whereas $K$. lactis was correlated with the presence 37 of ketones, ethyl acetate and secondary alcohols. In conclusion, this study 38 shows the heterogeneous potential of dairy yeasts to contribute to final cheese 39 flavour. 


\section{INTRODUCTION}

Yeasts play an important role in proteolysis, lipolysis, fermentation of residual lactose, and assimilation of lactic and citric acid during the ripening of some cheeses, contributing to aroma development and to the rheological properties of the final dairy product (McSweeney, 2004). Moreover yeasts have been recovered from all stages of cheesemaking, as well as from milk, brine and dairy process equipment among others (Corbo, Lanciotti, Albenzio, \& Sinigaglia, 2001; Delavenne et al., 2011; Gardini et al., 2006; Seiler \& Busse, 1990).

Debaryomyces hansenii is the dominant yeast species found in most cheese varieties (Fleet, 1990; Fox, Guinee, Cogan, \& Mc.Sweeny, 2000). D. hansenii possesses the ability to grow at high salt concentrations, low $\mathrm{pH}$ and low water activity, as well as metabolising lactic and citric acids, which makes cheese a suitable environment for its proliferation (Breuer \& Harms, 2006). Lactose-fermenting yeasts Kluyveromyces lactis and Kluyveromyces marxianus are also regularly found in dairy products and milk. Their lactosefermenting ability promotes their growth in the cheese, where other yeasts are scarce. Besides these species, cheeses may often contain other yeast species, such as Yarrowia lipolytica, Geotrichum candidum and Saccharomyces cerevisiae (Fleet, 1990).

Cheese flavour is one of the most relevant attributes influencing consumers' acceptance and preference (Arora, Cormier, \& Lee, 1995), and is the result of a complex balance between various volatile and non volatile compounds, which individually do not reflect the overall odour and taste (Fox \& Wallace, 1997). Many volatile compounds have been implicated in cheese aroma, 
such as acids, esters, ketones, aldehydes, alcohols or sulphur compounds, and each dairy product has a characteristic and unique composition of volatile components (Plutowska \& Wardencki, 2007).

The contribution of yeasts to development of cheese aroma is considered positive in some instances, creating commercial interest in using selected strains as ripening cultures (Frohlich-Wyder, 2003; Romano, Capace, \& Jespersen, 2006). Several studies have shown that, in different cheeses, relevant yeast species contribute differently to volatile production. G. candidum and $Y$. lipolytica are known to produce considerable amounts of various volatile sulphur compounds; $K$. lactis, $K$. marxianus and $S$. cerevisiae have been found to produce primarily esters; and $D$. hansenii mainly produced branched-chain aldehydes and alcohols (Arfi, Spinnler, Tache, \& Bonnarme, 2002; Martin, Berger, Le Du, \& Spinnler, 2001; Spinnler, Berger, Lapadatescu, \& Bonnarme, 2001; Leclercq-Perlat, Corrieu, \& Spinnler, 2004; Sørensen, Gori, Petersen, Jespersen, \& Arneborg, 2011). However, these studies emphasised inter-species aroma production, with few surveys focussing on strain variation. Berger, Khan, Molimard, Martin, and Spinnler (1999) reported the production of different yields of sulphur compounds by G. candidum, depending on the strain selected, and Gori, Sørensen, Petersen, Jespersen, and Arneborg (2012) recently showed large strain variations in the production of flavour compounds by $D$. hansenii.

Iberian traditional cheeses made from ewes' and goats' milk have high intrinsic value, arising from their unique sensory characteristics, which makes them highly appreciated by consumers (Freitas \& Malcata, 2000). In 
previous studies, yeasts present during the ripening process of ewes' and goats' raw milk cheeses produced in a small traditional dairy in the Mediterranean area of Spain were identified (Padilla, Manzanares, \& Belloch, 2014). D. hansenii and K. lactis were the yeast species most frequently isolated from both kind of cheeses, and the former predominated at the end of ripening period. K. marxianus, although less frequent, was present during the first weeks of maturing. Moreover, results demonstrated genetic heterogeneity present in the isolates (Padilla et al., 2014), and their strain-dependent ability to generate bioactive compounds (García-Tejedor, Padilla, Salom, Belloch, \& Manzanares, 2013; Padilla et al., 2012). However, there is little knowledge about the impact of the yeast isolates on the final quality of the cheeses.

The objective of the present study was to further characterise both the aforementioned raw milk cheeses and their yeast microbiota, to gain a better understanding of the relationship between yeast ripening strains and cheese flavour. For this purpose, the volatile profile of the cheeses was characterised. Volatile compounds were extracted by Solid Phase Micro Extraction (SPME) and analysed by Gas Chromatography-Mass Spectrometry (CG-MS). Moreover, the ability of 14 yeast strains belonging to $D$. hansenii, $K$. lactis and $K$. marxianus species to grow in a defined medium and produce volatile compounds also present in ripened cheeses was assessed. 
115 Commercial semi-hard ewes' and goats' cheeses produced in an artisanal dairy farm sited in the rural Castello province (Spain) were analysed for

117 volatile compounds. The cheeses were made from raw milk coagulated with the addition of mesophilic lactic acid bacteria starters and plant (Cynara cardunculus) rennet (Abiasa Company, Pontevedra, Spain). After precipitation of proteins, the curd was cut with vertical and horizontal knives and crumbled manually. The remaining whey was removed first manually and afterwards using a press. After salting, cheeses were air-dried until the rind was formed and ripened in wooden shelves at $10-12^{\circ} \mathrm{C}$ and a relative humidity of $85-90 \%$ for 60 days.

Three cheeses from the same batch and from ewes' milk and goats' milk were analysed at the end of ripening period ( 3 batches $\times 2$ cheeses $=6$ samples). After the rind was removed, cheeses were cut in pieces and ground with $0.75 \mathrm{mg}$ butylated hydroxytoluene/20 $\mathrm{g}$ sample, wrapped in aluminium foil, vacuum-packed and stored at $-20^{\circ} \mathrm{C}$ until GC analysis.

\subsection{Yeast strains}

Fourteen yeast strains belonging to the species $K$. marxianus $(\mathrm{Km} 1-\mathrm{Km} 4)$, $K$. lactis $(\mathrm{KI} 1-\mathrm{KI} 5)$ and $D$. hansenii (Dh1-Dh5) isolated during the ripening process from the artisanal cheeses described above and with different genetic characteristics were used in this study (Padilla et al., 2014). Yeast strains were maintained on GPYA medium (2\% glucose, $0.5 \%$ peptone, $0.5 \%$ yeast extract and $2 \%$ agar, $\mathrm{pH} 5.5)$.

\subsection{Culture conditions and media}

Cheese-like medium (CLM; casamino acids $15 \mathrm{~g} \mathrm{~L}^{-1}$, sodium lactate $19 \mathrm{ml}$ $\mathrm{L}^{-1}$, yeast extract $1 \mathrm{~g} \mathrm{~L}^{-1}, \mathrm{CaCl}_{2} \mathrm{~g} \mathrm{~L}^{-1}, \mathrm{MgSO}_{4} 0.5 \mathrm{~g} \mathrm{~L}^{-1}, \mathrm{KH}_{2} \mathrm{PO}_{4} 6.8 \mathrm{~g} \mathrm{~L}^{-1}$, 
$\mathrm{NaCl} 10 \mathrm{~g} \mathrm{~L}^{-1}$ and lactose $28 \mathrm{~g} \mathrm{~L}^{-1}$ ) was prepared according to Kagkli et al. (2006) without addition of L-methionine. Flasks (100-mL) containing $50 \mathrm{~mL}$ of CLM were inoculated with $10^{6}$ cells $\mathrm{mL}^{-1}$ from overnight pre-cultures grown in GPY medium (GPYA without agar) at $28^{\circ} \mathrm{C}$ and $150 \mathrm{rpm}$. CLM cultures were incubated over $48 \mathrm{~h}$ at $28^{\circ} \mathrm{C}$ and $150 \mathrm{rpm}$. At the end of the incubation period, samples were taken for OD600 measurement. Yeast cells were removed by centrifugation $(3220 \times \mathrm{g}, 10 \mathrm{~min})$ and culture $\mathrm{pH}$ was measured. Lactose and L-lactic acid were quantified in the supernatants using Roche enzymatic kits (Darmstadt, Germany). For each strain, three replicate cultures were analysed and a control without yeast inoculation was also included.

2.4 Analysis of headspace volatile compounds by SPME GC-MS

An Agilent HP 7890 series II GC (Hewlett- Packard, Palo Alto, CA, USA) with an HP 5975C mass selective detector (Hewlett-Packard) equipped with Gerstel MPS2 multipurpose sampler (Gerstel, Mülheim an der Ruhr, Germany) was used in all experiments. The volatile components of the samples were extracted by SPME. All extractions were carried out using a DVB/CAR/PDMS (divinylbenzene/carboxen/polydimethylsiloxane) fibre of 50/30 mm film thickness (Supelco, Bellefonte, PA, USA). The fiber was conditioned as indicated by the manufacturer prior to use in order to remove any possible contaminants. For cheeses, $5 \mathrm{~g}$ of product was placed in a 20 $\mathrm{mL}$ headspace vial sealed with a PTFE-faced silicone septum. The vial was maintained at $50^{\circ} \mathrm{C}$ for 15 min to equilibrate the headspace, and then the fiber was exposed over $30 \mathrm{~min}$ at the same temperature. Before each injection, the fiber was baked at $250^{\circ} \mathrm{C}$ for $10 \mathrm{~min}$. Each sample was 
analysed in triplicate. For CLM yeast cultures, $7 \mathrm{~mL}$ of supernatant plus 1.4 $\mathrm{g}$ of $\mathrm{NaCl}$ were added to a $20 \mathrm{~mL}$ headspace vial sealed with a PTFE-faced silicone septum. The vial was kept at $50^{\circ} \mathrm{C}$ for $15 \mathrm{~min}$ to equilibrate the headspace. The SPME fiber was then exposed to the headspace while maintaining the sample at $30^{\circ} \mathrm{C}$ for $15 \mathrm{~min}$. During extraction, the sample was agitated continuously in pulses of $10 \mathrm{sec}$ at $250 \mathrm{rpm}$. Before and after each injection, the fiber was baked at $250^{\circ} \mathrm{C}$ for 10 and $5 \mathrm{~min}$, respectively. Each sample was analysed twice.

After the extraction step, the analytes were thermally desorbed for $5 \mathrm{~min}$ from the fiber into the injector port of the GC-MS operating at $240^{\circ} \mathrm{C}$ in splitless mode. The compounds were then separated using a DB-624 capillary column J \& W Scientific (Agilent Technologies, Santa Clara, CA, USA) $(30 \mathrm{~m}, 0.25 \mathrm{~mm}$ i.d., film thickness $1.4 \mu \mathrm{m})$. For volatile analysis, the GC oven temperature program began at $40^{\circ} \mathrm{C}$, where it was held for $5 \mathrm{~min}$, then ramped to $100^{\circ} \mathrm{C}$ at $3^{\circ} \mathrm{C} \mathrm{min}-1$ and maintained for $5 \mathrm{~min}$, then to $150^{\circ} \mathrm{C}$ at $3^{\circ} \mathrm{C} \mathrm{min}-1$ and to $210^{\circ} \mathrm{C}$ at $4^{\circ} \mathrm{C} \mathrm{min}^{-1}$, and, finally, held at $210^{\circ} \mathrm{C}$ for $5 \mathrm{~min}$. Mass spectra were obtained by electron impact at $70 \mathrm{eV}$, and data were acquired across the range $29-400$ amu (scan mode).

Compounds were identified by comparison with mass spectra from the library database (Nist'05), Kovats retention index (Kovats, 1965) and by comparison with authentic standards. The quantification of volatile compounds was done in SCAN mode using total ion chromatograms (TIC). The results were expressed as abundance units $\left(\mathrm{AU} \times 10^{-6}\right)$. Volatile compounds quantitated from CLM control were subtracted from each yeastinoculated medium. 


\subsection{Statistical evaluation}

The effect of yeasts on the generation of volatile compounds in CLM was tested by one-way analysis of variance (ANOVA). Differences between sample means were analysed according to Fisher's least significant difference (LSD) test. Principal component analysis (PCA) was used to test relationships among yeast species, $\mathrm{pH}$, lactose and lactate consumption and main volatile compounds. Statistical analysis was performed using the statistic software XLSTAT, 2009.4.03 (Addinsoft, Barcelona, Spain).

\section{RESULTS}

\subsection{Volatile compounds in ewes'and goats'milk cheeses}

Sixty-five volatile compounds were quantitied in the headspace of Mediterranean ewes' and goats' cheeses (Table 1). They were classified into acids (14), esters (18), ketones (9), aldehydes (5), alcohols (17), terpenes (1) and sulphur compounds (1). Four of the sixty-five compounds were not present in the ewe's cheese, while eight of them were not present in the headspace of goat's cheese. As expected, most of the volatiles found in these cheeses have been previously reported in other varieties of ewes' and goats' raw milk cheeses (Table 1).

Esters and alcohols were the most abundant chemical families identified in the headspace of the Mediterranean cheeses studied, whereas, quantitatively, carboxylic acids were the most abundant volatiles. Among short and medium-chain carboxylic acids, the most abundant were acetic, butanoic, hexanoic, octanoic and decanoic acids, although branched-chain fatty acids such as 3-methylbutanoic and 2-methylbutanoic acids were also 
found in both cheeses. Among esters, ethyl esters were the most abundant, although propyl- and branched-chain esters were also identified. Methyl ketones were the most abundant ketones detected in these products while aldehydes were not major components in these cheeses.

\subsection{Yeast growth in CLM and production of volatile compounds} Growth and aromatic profile from pure cultures of yeast strains belonging to D. hansenii, K. lactis and K. marxianus were determined. All yeast strains were able to grow in a liquid medium mimicking cheese composition (CLM). Lactose and lactate concentrations and $\mathrm{pH}$ values after $48 \mathrm{~h}$ of growing in CLM were determined. Kluyveromyces strains depleted the available lactose almost completely. K. lactis consumed around $5 \%$ lactate, while lactate consumption by $K$. marxianus strains was around $16 \%$. When grown in CLM, Kluyveromyces strains increased the $\mathrm{pH}$ from 5 to 5.2-5.8. D. hansenii strains grew in CLM, consumed around $25 \%$ of lactose and 5 $\%$ of lactate, and the $\mathrm{pH}$ value increased to 5.6-6.6.

Volatile compounds detected in the headspace of CLM are summarised in Tables 2 and 3 . Only compounds which were also found in the Mediterranean cheeses (Table 1) are listed in Table 2, while Table 3 shows other volatile compounds detected in the headspace of CLM.

As observed in this study, yeasts were able to produce 27 compounds of those compounds found in the cheeses, including 6 acids, 7 esters, 3 ketones, 2 aldehydes and 9 alcohols (Table 2). Interestingly, the volatile composition of the headspace of CLM showed inter-species and inter-strain variations. General variations can be seen in Fig. 1, which shows volatile 
compounds classified by chemical groups and yeast species. K. marxianus and $K$. lactis were the best producers of esters and alcohols, without significant differences between the two species. Similar production of aldehydes was found for $K$. marxianus and $D$. hansenii, while the former was the best acid producer. In general, $D$. hansenii produced the lowest levels of volatile compounds in the conditions tested. Moreover, standard deviations indicated large strain variations for $D$. hansenii.

Among D. hansenii strains (Table 2), Dh1 produced the highest levels of total esters and alcohols. K. marxianus species was prominent due to the production of acetic acid. Production of octanoic acid was restricted to $K$. marxianus species, with $\mathrm{Km} 3$ being the best producer strain. $K$. marxianus $\mathrm{Km} 2$ stood out as the leading producer of total esters, due to the high production of 3-methyl-1-butanol acetate, the level of which was almost tenfold higher than that produced by $K$. lactis strains. Among esters, $K$. lactis strains produced primarily ethyl acetate. Interestingly, ethyl octanoate production was restricted to $K$. marxianus $\mathrm{Km} 1$ and $\mathrm{Km} 2$ under the conditions tested. With the exception of 2-pentanone production by Dh4, ketone production was restricted to $K$. lactis strains. In contrast, none of the $K$. lactis strains were able to produce aldehydes. Only two aldehydes were detected after yeast growth in CLM: benzaldehyde produced by $K$. marxianus $\mathrm{Km} 3$ and $\mathrm{Km} 4$ and 3-methylbutanal produced by $D$. hansenii Dh1 and Dh5. Regarding alcohol production, K. lactis produced 9 different volatiles, although $K$. marxianus strains $\mathrm{Km} 1, \mathrm{Km} 2$ and $\mathrm{Km} 3$ stood out as the best total alcohol producers, given the production of phenylethyl alcohol. Neither $K$. marxianus nor $D$. hansenii species were able to produce 2- 
heptanol and 2-nonanol. Moreover 2,3-butanediol was not detected after growth of $D$. hansenii in CLM, while $K$. marxianus strains were the best producers of such compounds (Table 2). Apart from these compounds, 23 more volatiles compounds were identified

\subsection{Principal component analysis}

Finally, a PCA model was developed using a dataset with 14 yeast strains and 30 variables, comprising 27 volatiles (those present in cheeses and CLM, Table 2), lactose and lactate consumption and $\mathrm{pH}$ of the medium (Fig. 2). Two principal components were able to explain $70.5 \%$ of the total variance observed. Principal component 1 (PC1) accounted for $39.6 \%$ of the variance while $\mathrm{PC} 2$ accounted for $30.9 \%$. PC1 differentiated the incubations by the yeast genera inoculated. Kluyveromyces strains appeared in the positive part of PC1, while Debaryomyces was situated in 
the negative side. Kluyveromyces strains were related to the maximum production of volatile compounds and to the highest lactose consumption. On the other hand, growth of $D$. hansenii was associated with the highest

\section{DISCUSSION}

This study provides a characteristic fingerprint of volatiles present in Mediterranean cheeses and indicates the metabolic potential of ripening yeast strains to impact on cheese flavour. The proportion of volatile compounds depends on the extraction method used, and in this case a SPME technique with DVB/CAR/PDMS fibres was employed. The method used allowed comparisons among the different yeast strains, since the volatile compounds were obtained on a semi-quantitative basis.

The present research demonstrates the ability of $K$. marxianus and $K$. lactis, and to a lesser extent $D$. hansenii strains, to produce key volatile compounds characteristic of the cheeses from which they were isolated (Table 1 and 2). All the strains tested in this study were able to grow in a defined cheese-like medium (CLM) containing lactose, lactate and casamino acids and generate volatile compounds. Although these 
conditions differ from real cheese, this medium has been successfully used for screening purposes of yeast species and strains with potential use in cheese ripening (Kagkli et al., 2006; Spinnler et al., 2001). As expected, D. hansenii strains consumed less lactose than Kluyveromyces, and this might account for the lower production of aroma compounds in CLM. The prevalence of $D$. hansenii during ripening in different kind of cheeses has been reported by several authors (Fleet, 1990; Fox \& Wallace, 1997; Fox et al., 2000) and it is considered as an obvious candidate for starter cultures (Bockelmann, 2002). Recently, Gori et al. (2012) reported the potential of $D$. hansenii strains to increase the nutty/malty flavour of cheese due to the production of aldehydes, although large strain variations were found. In this study and under the conditions tested, 3 branched-chain aldehydes (2-methylpropanal, 3-methylbutanal and 2-methylbutanal) were only produced by $D$. hansenii, with a large interstrain variation. 2-Methylpropanal and 2-methylbutanal derived from the catabolism of valine and isoleucine, respectively, were only detected in CLM, whereas 3-methylbutanal derived from leucine was also detected in cheeses characterised here. Aldehydes are potent odorants in several cheese varieties, although they are considered transitory compounds because they are quickly reduced to primary alcohols (Curioni \& Bosset, 2002). In fact, the corresponding alcohols derived from the three branchedaldehydes (2-methyl-1-propanol, 3-methyl-1-butanol and 2-methyl-1butanol) were detected in the cheeses and in D. hansenii CLM, as also reported by Sørensen et al. (2011). 
Ester formation in cheese is mainly related to yeast metabolism (Molimard \& Spinnler, 1996) although some lactic acid bacteria and Micrococcaceae, as well as chemical reactions, can be responsible (Gripon, Monnet, Lamberet, \& Desmazeaud, 1991). Esters come from a reaction between an alcohol, derived from lactose fermentation or amino-acid catabolism, and a fatty acid or amino acid catabolite intermediate. Most esters detected in cheese are described as having sweet, fruity and floral notes. Although a fruity flavour is traditionally regarded as a defect in cheese varieties such as cheese varieties such as Parmigiano Reggiano (Meinhart \& Schreier, 1986). Ester production by Kluyveromyces strains has been reported by several authors (Arfi et al., 2002; Jiang, 1993; Leclercq-Perlat et al., 2004; Martin et al., 2001). Ethyl acetate was the main ester produced, although ethyl propanoate, propyl acetate, butyl acetate, ethyl butanoate and ethyl octanoate were also detected after growth of Kluyveromyces (Arfi et al., 2002; Leclercq-Perlat et al., 2004). Moreover, 2-phenylethyl acetate, 3methylbutyl ethanoate and 2-methylpropyl ethanoate are also produced by Kluyveromyces strains (Jiang, 1993; Leclercq-Perlat et al., 2004), but strainspecific variations were not addressed. The present results confirm ethyl acetate as one of the primarily esters formed by Kluyveromyces strains, together with the production of 3-methyl-1-butanol acetate by two strains of K. marxianus. In total, K. marxianus and $K$. lactis strains respectively produced 20 and 16 different kinds of esters, respectively, (Table 2 and 3) highlighting the capability of the genus Kluyveromyces for ester production. Production of ethyl octanoate, restricted to $K$. marxianus strains under the 
conditions tested, was also reported by Leclercq-Perlat et al. (2004). These authors also observed that the ester production efficiency of $K$. marxianus was higher than that of $D$. hansenii, in agreement with the results obtained here. With the exception of two ester compounds, the five $K$. lactis strains tested produced the same ester profile, whereas $K$. marxianus strains differed in seven esters. These results suggest a lower inter-strain variation in $K$. lactis than in K. marxianus.

Several of the potential alcohols which may be precursors of the aforementioned esters were also identified in yeast CLM. Those alcohols were also detected after the growth of $D$. hansenii strains, where production of esters was negligible. It has been suggested that a highly hydrolytic activity towards esters in $D$. hansenii strains might be the reason for the limited accumulation of ester compounds (Besancon, Ratomahenina, \& Galzy, 1995). The $D$. hansenii strains tested in this study have also been characterised as having hydrolytic activity towards fatty acid esters (Padilla et al., 2014).

Interestingly this study shows that only $K$. lactis strains were able to produce 2-pentanone, 2-heptanone and 2-nonanone, which were characteristic compounds of those cheeses from which they were isolated (Table 1 and 2). A previous study has shown the ability of $K$. lactis to produce other kinds of ketones, such as 3-hydroxy-2-butanone and 1hydroxy-2-propanone, from a medium containing glucose, yeast extract and vitamins (Jiang, 1993). However, to the best of our knowledge, ketones generation by yeasts in a medium mimicking cheese composition has not been reported. Methyl ketones are associated with fruity, floral and musty 
notes, and their synthesis has been related to the enzymatic activity of moulds in surface-ripened cheeses (Curioni \& Bosset, 2002). Short-chain free fatty acids, predominant components of the flavour of many cheeses such as those described here, were mainly characteristics of $K$. strains. 


\section{CONCLUSIONS}

This study has confirmed the potential of dairy yeasts to contribute to the final cheese flavour. Moreover, species and strain variations were significant, indicating a heterogeneous contribution to volatile compound production and the feasibility of strain selection to modulate cheese flavour and aroma. However, the development of suitable yeast starters requires further studies, since complex interactions among cheese microbiota should be taken into account. Characterization of enzyme activities involved in flavour formation by dairy yeasts is in progress.

\section{Acknowledgments}

Authors thank grants Consolider Ingenio Fun- $\underline{-}-$ Food, CSD2007-00063, INIA RM2007-00010 and AGL2012-38884-C02-01 for financial support. BP thanks CSIC for a JAE Predoc contract. Authors are grateful to the Cheese Company "Los Corrales" for kindly supplying the cheese samples.

\section{References}

Arfi, K., Spinnler, H., Tache, R., \& Bonnarme, P. (2002). Production of volatile compounds by cheese-ripening yeasts: requirement for a methanethiol donor for S-methyl thioacetate synthesis by Kluyveromyces lactis. Applied Microbiology and Biotechnology, 58, 503-510.

Arora, G., Cormier, F., \& Lee, B. (1995). Analysis of odor-active volatiles in Cheddar cheese headspace by multidimensional GC/MS/Sniffing. Journal of Agricultural and Food Chemistry, 43, 748-752. 
Berger, C., Khan, J. A., Molimard, P., Martin, N., \& Spinnler, H. E. (1999). Production of sulfur flavors by ten strains of Geotrichum candidum. Applied and Environmental Microbiology, 65, 5510-5514.

Besancon, X., Ratomahenina, R., \& Galzy, P. (1995). Isolation and partial characterization of an esterase (EC 3.1.1.1) from a Debaryomyces hansenii strain. Netherlands Milk and Dairy Journal, 49, 97-110.

Bockelmann, W. (2002). Development of defined surface starter cultures for the ripening of smear cheeses. International Dairy Journal, 12, 123131. 437.

Breuer, U., \& Harms, H. (2006). Debaryomyces hansenii — an extremophilic yeast with biotechnological potential. Yeast, 23, 415-

Carbonell, M., Núñez, M, \& Fernández-García, E. (2002). Evolution of the volatile components of ewe raw milk La Serena cheese during ripening. Correlation with flavour characteristics. Le Lait, 82, 683698.

Condurso, C., Verzera, A., Romeo, V., Ziino, M., \& Conte, F. (2008). Solidphase microextraction and gas chromatography mass spectrometry analysis of dairy product volatiles for the determination of shelf-life. International Dairy Journal, 18, 819-825.

Corbo, M. R., Lanciotti, R., Albenzio, M., \& Sinigaglia, M. (2001). Occurrence and characterization of yeasts isolated from milks and dairy products of Apulia region. International Journal of Food Microbiology, 69, 147-152. 
Curioni, P. M. G., \& Bosset, J. O. (2002). Key odorants in various cheese types as determined by gas chromatography-olfactometry. International Dairy Journal, 12, 959-984.

Delavenne, E., Mounier, J., Asmani, K., Jany, J.-L., Barbier, G., \& Le Blay, G. (2011). Fungal diversity in cow, goat and ewe milk. International Journal of Food Microbiology, 151, 247-251.

Delgado, F. J., González-Crespo, J., Cava, R., García-Parra, J., \& Ramírez, R. (2010). Characterisation by SPME-GC-MS of the volatile profile of a Spanish soft cheese P.D.O. Torta del Casar during ripening. Food Chemistry, 118, 182-189.

Delgado, F. J., González-Crespo, J., Cava, R., \& Ramírez, R. (2011). Formation of the aroma of a raw goat milk cheese during maturation analysed by SPME-GC-MS. Food Chemistry, 129, 1156-1163.

Fernández-García, E., Carbonell, M., Gaya, P., \& Nuñez, M. (2004). Evolution of the volatile components of ewes raw milk Zamorano cheese. Seasonal variation. International Dairy Journal, 14, 701-711.

Fleet, G. H. (1990). A review: Yeasts in dairy products. Journal of Applied Bacteriology, 68, 199-211.

Fox, P. F., \& Wallace, J. M. (1997). Formation of misvor compounds in cheese. Advances in Applied Microbiology, 45, 17-85.

Fox, P. F., Guinee, T. P., Cogan, T. M., \& Mc.Sweeny, P. L. H. (2000). Fundamentals of cheese science. (1st ed.). Gaithersburg: Aspen publuishers, Inc., (Chapter 10).

Freitas, C., \& Malcata, X. F. (2000). Microbiology and biochemistry of cheeses with Appélation d'Origine Protegée and manufactured in the 
Iberian Peninsula from ovine and caprine milks. Journal of Dairy Science, 83, 584-602.

490

491

492

493

494

495

496

497

498

499

500

501

502

503

504

505

506

507

508

509

510

511

512

Frohlich-Wyder, M. T. (2003). Yeasts in dairy products. In T. Boekhout \& V. Robert (Eds.), Yeasts in food beneficial and detrimental aspects (pp. 209-237). Hamburg: Behis Verlag.

García-Tejedor, A., Padilla, B., Salom, J. B., Belloch, C., \& Manzanares, P. (2013). Dairy yeasts producemilk protein-derived antihypertensive hydrolysates. Food Research International, 53, 203-208.

Gardini, F., Tofalo, R., Belletti, N., Iucci, L., Suzzi, G., Torriani, S., Guerzoni, M. E., \& Lanciotti, R. (2006). Characterization of yeasts involved in the ripening of Pecorino Crotonese cheese. Food Microbiology, 23, 641-648.

Gori, K., Sørensen, L. M., Petersen, M. A., Jespersen, L., \& Arneborg, N. (2012). Debaryomyces hansenii strains differ in their production of flavor compounds in a cheese-surface model. Microbiology Open, 1, 161-168.

Gripon, J. C., Monnet, V., Lamberet, G., \& Desmazeaud, M. J. (1991). Microbial enzymes in cheese ripening. In P. F. Fox (Ed.), Food enzymes (pp. 131-168). London: Elsevier Applied Science.

Horwood, J. F., Stark, W., \& Hull, R. R. (1987). A "fermented, yeasted" flavour defect in Cheddar cheese. Australian Journal of Dairy Technology, 42, 25-26.

Izco, J. M., \& Torre, P. (2000). Characterisation of volatile flavour compounds in Roncal cheese extracted by the 'purge and trap' method and analysed by GC-MS. Food Chemistry, 70, 409-417. 
Jiang, J. (1993). Identification of flavour volatile compounds produced by Kluyveromyces lactis. Biotechnology Techniques, 7, 863-866.

Kagkli, D.-M., Tâche, R., Cogan, T., Hill, C., Casaregola, S., \& Bonnarme, P. (2006). Kluyveromyces lactis and Saccharomyces cerevisiae, two potent deacidifying and volatile-sulphur-aroma-producing microorganisms of the cheese ecosystem. Applied Microbiology and Biotechnology, 73, 434-442.

Kovats, E. S. (1965). Gas chromatographic characterization of organic substances in the retention index system. In J. C. Giddings \& R. A. Keller (Eds.), Advances in chromatography (pp. 229-247). New York: Marcel Dekker Inc.

Kuzdzal-Savoie, S. (1980). Determination of free fatty acids in milk and milk products. In Annual Bulletin 118 (pp. 53-66). Brussels: International Dairy Federation.

Larráyoz, P., Addis, M., Gauch, R., \& Bosset, J. O. (2001). Comparison of dynamic headspace and simultaneous distillation extraction techniques used for the analysis of the volatile components in three European PDO ewes' milk cheeses. International Dairy Journal, 11, 911-926.

Leclercq-Perlat, M. N., Corrieu, G., \& Spinnler, H. E. (2004). Comparison of volatile compounds produced in model cheese medium deacidified by Debaryomyces hansenii or Kluyveromyces marxianus. Journal of Dairy Science, 87, 1545-1550.

López del Castillo-Lozano, M., Delile, A., Spinnler, H. E., Bonnarme, P., \& Landaud, S. (2007). Comparison of volatile sulphur compound 
production by cheese-ripening yeasts from methionine and methionine-cysteine mixtures. Applied Microbiology and Biotechnology, 75, 1447-1454.

Martin, N., Berger, C., Le Du, C., \& Spinnler, H. E. (2001). Aroma compound production in cheese curd by coculturing with selected yeast and bacteria. Journal of Dairy Science, 84, 2125-2135. Journal of Dairy Technology, 57, 127-144. 
Romano, P., Capace, A., \& Jespersen, L. (2006). Taxonomic and ecological diversity of food and beverage yeasts. In A. Querol \& G. H. Fleet (Eds.), The yeast handbook-Yeasts in food and beverages (pp. 1353). Heidelberg: Springer-Verlag Berlin.

Seiler, H., \& Busse, M. (1990). The yeasts of cheese brines. International Journal of Food Microbiology, 11, 289-303.

Sørensen, L. M., Gori, K., Petersen, M. A., Jespersen, L., \& Arneborg, N. (2011). Flavour compound production by Yarrowia lipolytica, Saccharomyces cerevisiae and Debaryomyces hansenii in a cheesesurface model. International Dairy Journal, 21, 970-978.

Spinnler, H. E., Berger, C., Lapadatescu, C., \& Bonnarme, P. (2001). Production of sulfur compounds by several yeasts of technological interest for cheese ripening. International Dairy Journal, 11, 245-252. 
Fig. 1. Total volatile compounds abundance by chemical group (expressed

579 as $\left.\mathrm{AU} \times 10^{6}\right)$ in the headspace of CLM supernatants after yeast growth: $\mathrm{Km}$ :

$580 \quad K l u y v e r o m y c e s$ marxianus; Kl: Kluyveromyces lactis; Dh: Debaryomyces

581 hansenii. Data are mean \pm SD of levels of volatile compounds produced by

582 the different strains tested. Different letters in the same chemical group

583 indicate significant differences $(p<0.05)$ among yeast species.

584 Fig. 2. Loadings of the first two principal components (PC1-PC2) of the 585 analysed parameters $\mathrm{pH}$, percentage of lactose and lactate consumption 586 and volatile compounds) of CLM after growth of different yeast strains: $587 \mathrm{Km} 1-\mathrm{Km} 4$ (Kluyveromyces marxianus), KI1-KI5 (Kluyveromyces lactis), 588 Dh1-Dh5 (Debaryomyces hansenii). 
Table 1. Abundance of volatile compounds (expressed as $A U \times 10^{6}$ extracted by

591 SPME) in the headspace of the raw milk cheeses ${ }^{a}$.

\begin{tabular}{|c|c|c|c|c|c|}
\hline Compound & $L R I^{b}$ & $\mathrm{Rl}^{\mathrm{c}}$ & Goats' cheese & Ewes' cheese & $\begin{array}{l}\text { Previously } \\
\text { reported }^{d}\end{array}$ \\
\hline \multicolumn{6}{|l|}{ Acids } \\
\hline Acetic acid & 709 & $A$ & $196.2 \pm 13.6$ & $224.6 \pm 31.6$ & $1-7$ \\
\hline Propanoic acid & 815 & A & $3.2 \pm 0.1$ & $9.5 \pm 1.6$ & $3-7$ \\
\hline 2-Methylpropanoic acid & 852 & $A$ & $27.3 \pm 5.3$ & $12.5 \pm 0.1$ & $1,3-6$ \\
\hline Butanoic acid & 891 & $A$ & $482.7 \pm 15.0$ & $216.3 \pm 15.6$ & $1-7$ \\
\hline 3-Methylbutanoic acid & 932 & $A$ & $30.2 \pm 7.1$ & $20.8 \pm 1.6$ & $1,3,5-7$ \\
\hline 2-Methylbutanoic acid & 939 & $A$ & $31.8 \pm 7.8$ & $15.1 \pm 2.0$ & 7 \\
\hline Pentanoic acid & 971 & $A$ & $2.7 \pm 0.3$ & $1.3 \pm 0.1$ & $3,4,7$ \\
\hline Hexanoic acid & 1080 & $A$ & $676.6 \pm 19.5$ & $219.5 \pm 9.6$ & $1-4,6,7$ \\
\hline Heptanoic acid & 1165 & $A$ & $4.7 \pm 0.2$ & $2.0 \pm 0.1$ & 3,4 \\
\hline Octanoic acid & 1264 & A & $271.4 \pm 7.9$ & $67.1 \pm 1.7$ & $2-4$ \\
\hline Benzenecarboxylic acid & 1283 & $A$ & $2.0 \pm 0.3$ & $1.4 \pm 0.1$ & 2 \\
\hline Nonanoic acid & 1357 & $A$ & $2.3 \pm 0.1$ & nd & 2,4 \\
\hline Decanoic acid & 1453 & $A$ & $128.2 \pm 9.5$ & $33.0 \pm 1.8$ & $2-4$ \\
\hline Dodecanoic acid & 1646 & B & $3.1 \pm 0.4$ & $0.9 \pm 0.1$ & 2,3 \\
\hline \multicolumn{6}{|l|}{ Esters } \\
\hline Ethyl acetate & 641 & A & $7.3 \pm 2.1$ & $25.4 \pm 5.2$ & $1-7$ \\
\hline Propyl acetate & 743 & $A$ & $1.1 \pm 0.1$ & $4.1 \pm 2.0$ & $1,4,5,7$ \\
\hline 1-Methylpropyl acetate & 787 & $\mathrm{~B}$ & nd & $10.8 \pm 7.4$ & 1,7 \\
\hline Ethyl butanoate & 828 & $A$ & $18.9 \pm 6.3$ & $11.2 \pm 2.5$ & $1-5,7$ \\
\hline Butyl acetate & 844 & $A$ & nd & $0.6 \pm 0.1$ & $1,5,7$ \\
\hline 3-Methyl-1-butanol acetate & 907 & $A$ & $5.6 \pm 0.7$ & $3.8 \pm 0.3$ & 1,7 \\
\hline Propyl butanoate & 923 & $A$ & $4.6 \pm 0.4$ & $2.8 \pm 0.7$ & $3-5,7$ \\
\hline $\begin{array}{l}\text { 1-Methylpropyl butanoate } \\
\text { 2-Methylpropyl 2-methyl }\end{array}$ & 960 & B & $4.9 \pm 0.6$ & $7.5 \pm 0.3$ & - \\
\hline butanoate & 979 & B & $0.6 \pm 0.1$ & nd & - \\
\hline Ethyl hexanoate & 1027 & A & $28.9 \pm 13.5$ & $15.6 \pm 1.0$ & $1-7$ \\
\hline 3-Methylbutyl butanoate & 1084 & B & $6.2 \pm 0.1$ & nd & - \\
\hline 2-Propenyl hexanoate & 1111 & B & $0.5 \pm 0.0$ & nd & - \\
\hline Propyl hexanoate & 1123 & $A$ & $6.3 \pm 0.1$ & $2.1 \pm 0.4$ & 5,7 \\
\hline 1-Methylbutyl butanoate & 1175 & $B$ & $1.4 \pm 0.0$ & $0.9 \pm 0.1$ & - \\
\hline Ethyl 2-methyl-propanoate & 1182 & B & $1.4 \pm 0.1$ & nd & 1 \\
\hline Ethyl octanoate & 1225 & A & $16.8 \pm 1.4$ & $3.9 \pm 0.4$ & $1,3-7$ \\
\hline Propyl octanoate & 1322 & B & 1.00 .0 & nd & - \\
\hline Ethyl decanoate & 1425 & $A$ & $7.5 \pm 0.8$ & $1.5 \pm 0.1$ & $1,2,4-6$ \\
\hline \multicolumn{6}{|l|}{ Ketones } \\
\hline Acetone & 529 & $A$ & $1.2 \pm 0.1$ & $1.1 \pm 0.3$ & 2 \\
\hline 2-Butanone & 635 & $A$ & $43.2 \pm 10.7$ & $529.3 \pm 26.3$ & $1,3-7$ \\
\hline 2-Pentanone & 729 & $A$ & $41.7 \pm 2.8$ & $14.0 \pm 6.2$ & $1,4-7$ \\
\hline 3-Hydroxy-2-butanone & 779 & $A$ & $3.1 \pm 0.6$ & $31.8 \pm 7.9$ & 5,6 \\
\hline 2-Hexanone & 833 & $A$ & $1.6 \pm 0.0$ & nd & $5-7$ \\
\hline 2-Heptanone & 932 & $A$ & $42.1 \pm 3.2$ & $3.7 \pm 1.6$ & $1,2,4-7$ \\
\hline
\end{tabular}




$\begin{array}{lccccc}\text { 8-Nonen-2-one } & \text { 1135 } & \mathrm{B} & 3.4 \pm 0.5 & \text { nd } & - \\ \text { 2-Nonanone } & \text { 1139 } & \mathrm{A} & 147.4 \pm 22.2 & 7.8 \pm 2.9 & 1,2,4-7 \\ \text { 2-Undecanone } & \text { 1344 } & \mathrm{A} & 3.2 \pm 0.6 & 0.6 \pm 0.1 & - \\ \text { Aldehydes } & & & & & \\ \text { 2-Propenal } & \text { 519 } & \mathrm{A} & 1.4 \pm 0.1 & 0.5 \pm 0.1 & 1,5,7 \\ \text { 3-Methylbutanal } & \text { 691 } & \mathrm{A} & 1.2 \pm 0.2 & 1.0 \pm 0.1 & 1-7 \\ \text { Hexanal } & \text { 838 } & \mathrm{A} & 0.8 \pm 0.1 & \mathrm{nd} & 1,2,5,7 \\ \text { Benzaldehyde } & 1017 & \mathrm{~A} & 1.1 \pm 0.1 & 1.6 \pm 0.2 & 2,3 \\ \text { Benzeneacetaldehyde } & \text { 1107 } & \mathrm{A} & 1.4 \pm 0.2 & 0.8 \pm 0.2 & 3 \\ \text { Alcohols } & & & & & \\ \text { Ethyl alcohol } & \text { 511 } & \mathrm{A} & 62.4 \pm 9.2 & 32.5 \pm 6.5 & 1,5-7 \\ \text { Isopropyl alcohol } & 538 & \mathrm{~A} & 3.0 \pm 0.5 & 1.6 \pm 0.3 & 5,7 \\ \text { 2-Propen-1-ol } & 610 & \mathrm{~B} & 3.8 \pm 0.4 & 2.7 \pm 1.0 & 1,5-7 \\ \text { 1-Propanol } & 615 & \mathrm{~A} & 16.7 \pm 1.5 & 20.6 \pm 6.8 & 1,4-6 \\ \text { 2-Butanol } & 647 & \mathrm{~A} & 133.2 \pm 13.4 & 461.4 \pm 32.5 & 1,3-5 \\ \text { 2-Methyl-1-propanol } & 682 & \mathrm{~A} & 1.0 \pm 0.1 & 0.4 \pm 0.1 & 1,5,6 \\ \text { 1-Methoxy-2-propanol } & 718 & \mathrm{~B} & 1.3 \pm 0.2 & 1.4 \pm 0.3 & 3,5,6 \\ \text { 1-Butanol } & 719 & \mathrm{~A} & 3.2 \pm 0.5 & 3.8 \pm 0.7 & 1,2,4-7 \\ \text { 2-Pentanol } & 747 & \mathrm{~A} & 68.2 \pm 5.3 & 10.7 \pm 3.9 & 1,4-7 \\ \text { 3-Methyl-1-butanol } & 793 & \mathrm{~A} & 18.3 \pm 0.8 & 6.6 \pm 0.9 & 1,3-7 \\ \text { 2-Methyl-1-butanol } & 796 & \mathrm{~A} & 2.8 \pm 0.2 & 1.2 \pm 0.1 & 7 \\ \text { 2,3-Butanediol } & 879 & \mathrm{~A} & 37.9 \pm 3.6 & 59.4 \pm 6.4 & - \\ \text { 1-Hexanol } & \text { 920 } & \mathrm{A} & 4.9 \pm 0.3 & 2.8 \pm 0.7 & 1,2,5,6 \\ \text { 2-Heptanol } & 944 & \mathrm{~A} & 71.2 \pm 6.9 & 14.2 \pm 5.9 & 1,4-7 \\ \text { 1-Heptanol } & 1022 & \mathrm{~A} & \mathrm{nd} & 0.8 \pm 0.1 & 1,7 \\ \text { 2-Nonanol } & 1147 & \mathrm{~A} & 12.1 \pm 1.1 & 2.7 \pm 0.7 & 1,4 \\ \text { Phenylethyl alcohol } & 1193 & \mathrm{~A} & 5.8 \pm 0.6 & 2.3 \pm 0.3 & - \\ \text { Terpenes } & & & & & \end{array}$

\section{Terpenes}

D-Limonene

1043 A nd

$39.2 \pm 1.4$

$1,2,4,5,7$

\section{Sulphur compounds}

Dimethyl sulfone

$\begin{array}{llll}1057 & \text { A } & 3.1 \pm 0.5 & 1.9 \pm 0.3\end{array}$

$\mathrm{AU}$ : Abundance units, the result of counting the total ion chromatogram (TIC) for each compound.

aValues are mean $\pm \operatorname{SD}(n=3)$.

bLinear retention indices (LRI) of the compounds eluted from the GC-MS using a DB-624 capillary column (J\&W Scientific $30 \mathrm{~m} \times 0.25 \mathrm{~mm}$ i.d. $\times 1.4 \mu \mathrm{m}$ film thickness).

'Reliability of identification (RI): A, mass spectrum and retention time identical with an authentic standard; B, tentative identification by mass spectrum.

'Compounds previously reported in ewes' and goats' raw milk cheeses. Reference numbers are as follows: (1) Carbonell, Núñez, \& Fernández-García, 2002; (2) Condurso, Verzera, Romeo, Ziino, \& Conte, 2008; (3) Delgado, González-Crespo, Cava, García-Parra, \& Ramírez, 2010; (4) Delgado, González-Crespo, Cava, \& Ramírez, 2011; (5) Fernández-García, Carbonell, Gaya, \& Nuñez, 2004; (6) Izco \& Torre, 2000 and (7) Larráyoz, Addis, Gauch, \& Bosset, 2001. nd: Not detected. 
Table 2. Volatile compounds (expressed as $A U \times 10^{6}$ extracted by HS-SPME) identified in the headspace of CLM after yeast growth ${ }^{a}$.

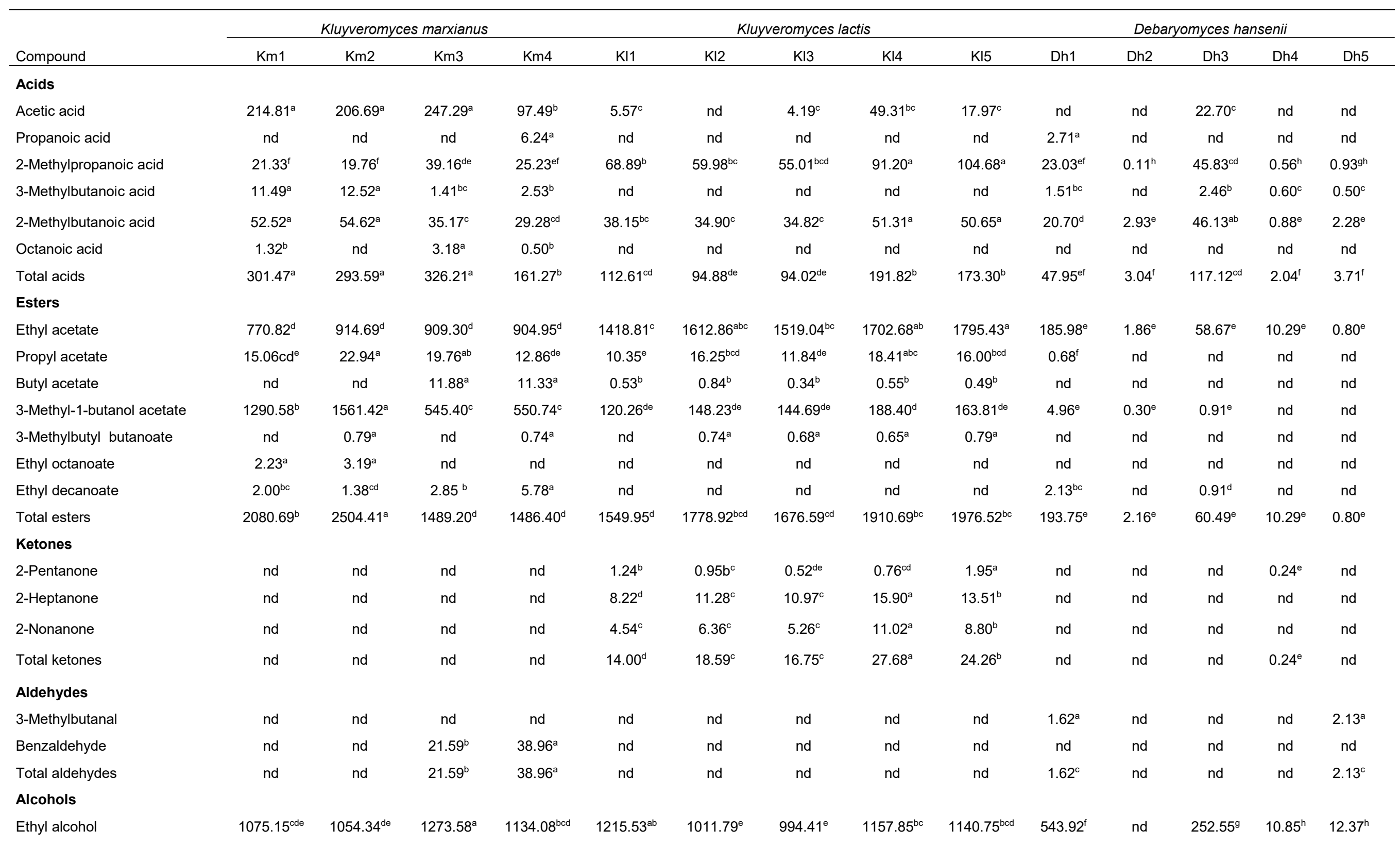




\begin{tabular}{|c|c|c|c|c|c|c|c|c|c|c|c|c|c|c|}
\hline 1-Propanol & $29.90^{c}$ & $26.35^{c}$ & $55.70^{\mathrm{b}}$ & $66.05^{a}$ & $16.34^{d}$ & $14.92^{\mathrm{de}}$ & $16.13^{d}$ & $12.09^{\mathrm{de}}$ & $10.85^{\text {ef }}$ & $7.15 \mathrm{f}^{\mathrm{g}}$ & $0.29^{h}$ & $2.95 \mathrm{~g}^{\mathrm{h}}$ & $0.52^{\mathrm{h}}$ & $0.33^{h}$ \\
\hline 2-Methyl-1-propanol & $193.25^{d}$ & $193.23^{d}$ & $187.82^{\mathrm{d}}$ & $156.24^{\mathrm{e}}$ & $283.99^{b}$ & $277.63^{b c}$ & $256.03^{c}$ & $285.64^{b}$ & $337.74^{\mathrm{a}}$ & $193.06^{d}$ & $10.53^{9}$ & $66.77^{f}$ & $9.97^{9}$ & $3.02^{\mathrm{g}}$ \\
\hline 3-Methyl-1-butanol & $1570.08^{\mathrm{cd}}$ & $1517.17^{\mathrm{cd}}$ & $1619.72^{\mathrm{bc}}$ & $1440.63^{d}$ & $1748.11^{\mathrm{ab}}$ & $1658.89^{a b c}$ & $1633.48^{\mathrm{abc}}$ & $1578.36^{\mathrm{cd}}$ & $1789.07^{a}$ & $591.30^{\mathrm{ef}}$ & $702.24^{\mathrm{e}}$ & $458.81^{f}$ & $87.48^{\mathrm{g}}$ & $31.85^{9}$ \\
\hline 2-Methyl-1-butanol & $942.22^{\mathrm{e}}$ & $932.17^{e}$ & $1228.13^{a}$ & $1181.01^{\mathrm{abc}}$ & $1144.75^{\mathrm{bcd}}$ & $1130.80^{\text {cd }}$ & $1110.76^{d}$ & $1111.02^{\mathrm{d}}$ & $1110.01^{d}$ & $1213.12^{\mathrm{ab}}$ & $191.44^{\mathrm{g}}$ & $825.22^{f}$ & $28.01^{\mathrm{h}}$ & $22.46^{\mathrm{h}}$ \\
\hline 2,3-Butanediol & $13.98^{b}$ & $11.58^{\mathrm{bc}}$ & $31.72^{\mathrm{a}}$ & $14.40^{\mathrm{b}}$ & $8.91^{\mathrm{cd}}$ & $2.03^{e}$ & $4.06^{\mathrm{e}}$ & $7.66^{d}$ & $7.88^{d}$ & nd & nd & nd & nd & nd \\
\hline 2-Heptanol & nd & nd & nd & nd & $6.11^{b}$ & $6.61^{b}$ & $5.78^{\mathrm{b}}$ & $7.64^{a}$ & $8.44^{\mathrm{a}}$ & nd & nd & nd & nd & nd \\
\hline 2-Nonanol & nd & nd & nd & nd & $8.37^{b}$ & $8.34^{b}$ & $7.65^{b}$ & $11.72^{\mathrm{a}}$ & $13.13^{a}$ & nd & nd & nd & nd & nd \\
\hline Phenylethyl alcohol & $1301.50^{\mathrm{a}}$ & $1291.65^{a}$ & $745.37^{b}$ & $578.62^{\mathrm{c}}$ & $282.76^{\text {de }}$ & $251.70^{\text {de }}$ & $286.85^{d}$ & $230.59^{\mathrm{de}}$ & $218.21^{\mathrm{e}}$ & $47.08^{f}$ & $230.40^{\text {de }}$ & $49.93^{f}$ & $15.12^{f}$ & $28.15^{f}$ \\
\hline Total alcohols & $5126.08^{a}$ & $5026.49^{\mathrm{ab}}$ & $5142.04^{a}$ & $4571.03^{\mathrm{cd}}$ & $4714.87^{\mathrm{bc}}$ & $4362.71^{d}$ & $4315.15^{d}$ & $4402.59^{c d}$ & $4636.08^{\mathrm{cd}}$ & $2595.63^{\mathrm{e}}$ & $1134.90^{\mathrm{g}}$ & $1656.23^{f}$ & $151.95^{h}$ & $98.18^{\mathrm{h}}$ \\
\hline
\end{tabular}


Table 3. Generation of volatile compounds (not found in the Mediterranean cheeses) in the headspace of CLM inoculated with yeasts.

\begin{tabular}{|c|c|c|c|c|c|}
\hline \multirow[b]{2}{*}{ Compound } & \multirow[b]{2}{*}{$\mathrm{LR} \mathrm{I}^{\mathrm{b}}$} & \multirow[b]{2}{*}{$\mathrm{RI}^{\mathrm{c}}$} & \multicolumn{3}{|c|}{ Yeast $^{\mathrm{a}}$} \\
\hline & & & K. marxianus & K. lactis & D. hansenii \\
\hline \multicolumn{6}{|l|}{ Esters } \\
\hline Ethyl propanoate & 738 & $A$ & $100^{c}$ & 100 & 80 \\
\hline Ethyl 2-methyl-propanoate & 785 & A & 100 & 100 & 40 \\
\hline 2-Methylpropyl acetate & 804 & $A$ & 100 & 100 & 20 \\
\hline Propyl propanoate & 837 & $A$ & 50 & 100 & 0 \\
\hline Ethyl 2-methyl-butanoate & 876 & $A$ & 100 & 100 & 40 \\
\hline Ethyl 3-methyl-butanoate & 879 & $A$ & 0 & 0 & 40 \\
\hline 2-Methylpropyl propanoate & 895 & $A$ & 75 & 100 & 20 \\
\hline 2-Methyl-1-butanol acetate & 909 & $A$ & 100 & 100 & 40 \\
\hline 3-Methyl-1-butanol propanoate & 995 & $A$ & 100 & 100 & 20 \\
\hline 2-Methyl-1-butanol propanoate & 999 & $A$ & 100 & 80 & 20 \\
\hline 2-Methylbutyl 2-methyl-propanoate & 1044 & $A$ & 50 & 100 & 40 \\
\hline 3-Methylbutyl 2-methyl-butanoate & 1128 & $A$ & 0 & 0 & 40 \\
\hline 2-Methylbutyl 2-methyl-butanoate & 1133 & $A$ & 0 & 0 & 40 \\
\hline 2-Phenylethyl acetate & 1317 & $A$ & 25 & 100 & 20 \\
\hline 2-Phenylethyl propanoate & 1407 & $A$ & 100 & 100 & 0 \\
\hline Phenylethyl butyrate & 1451 & $A$ & 100 & 100 & 20 \\
\hline \multicolumn{6}{|l|}{ Ketones } \\
\hline Methyl isobutyl ketone & 781 & B & 0 & 0 & 80 \\
\hline \multicolumn{6}{|l|}{ Aldehydes } \\
\hline Acetaldehyde & 469 & $A$ & 0 & 100 & 60 \\
\hline 2-Methylpropanal & 595 & $A$ & 0 & 0 & 60 \\
\hline 2-Methylbutanal & 700 & $A$ & 0 & 0 & 60 \\
\hline \multicolumn{6}{|l|}{ Alcohols } \\
\hline 3-Methyl-pentanol & 899 & $A$ & 0 & 100 & 80 \\
\hline 3,7-Dimethyl-6-octen-1-ol & 1285 & B & 100 & 100 & 20 \\
\hline \multicolumn{6}{|l|}{ Sulphur compounds } \\
\hline Methionol & 1060 & A & 100 & 100 & 20 \\
\hline
\end{tabular}

a Percentage of strains producing volatile compound in CLM media.

${ }^{\mathrm{b}}$ Refer to foodnote ${ }^{\mathrm{a}}$ in Table 1.

${ }^{\mathrm{c}}$ Refer to foodnote ${ }^{\mathrm{b}}$ in Table 1. 
Figure 1 Padilla et al., 2013

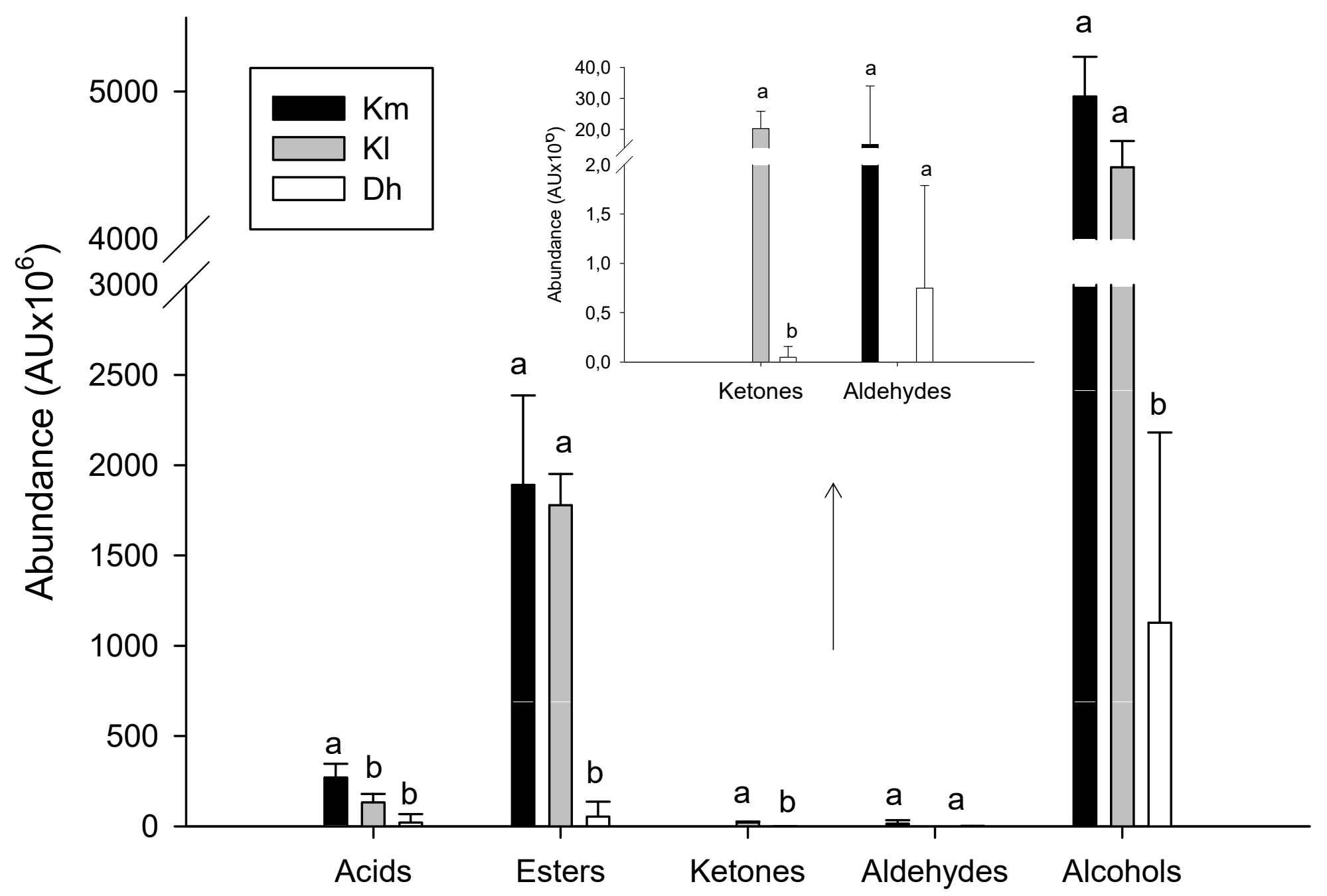


Figure 2 Padilla et al., 2013

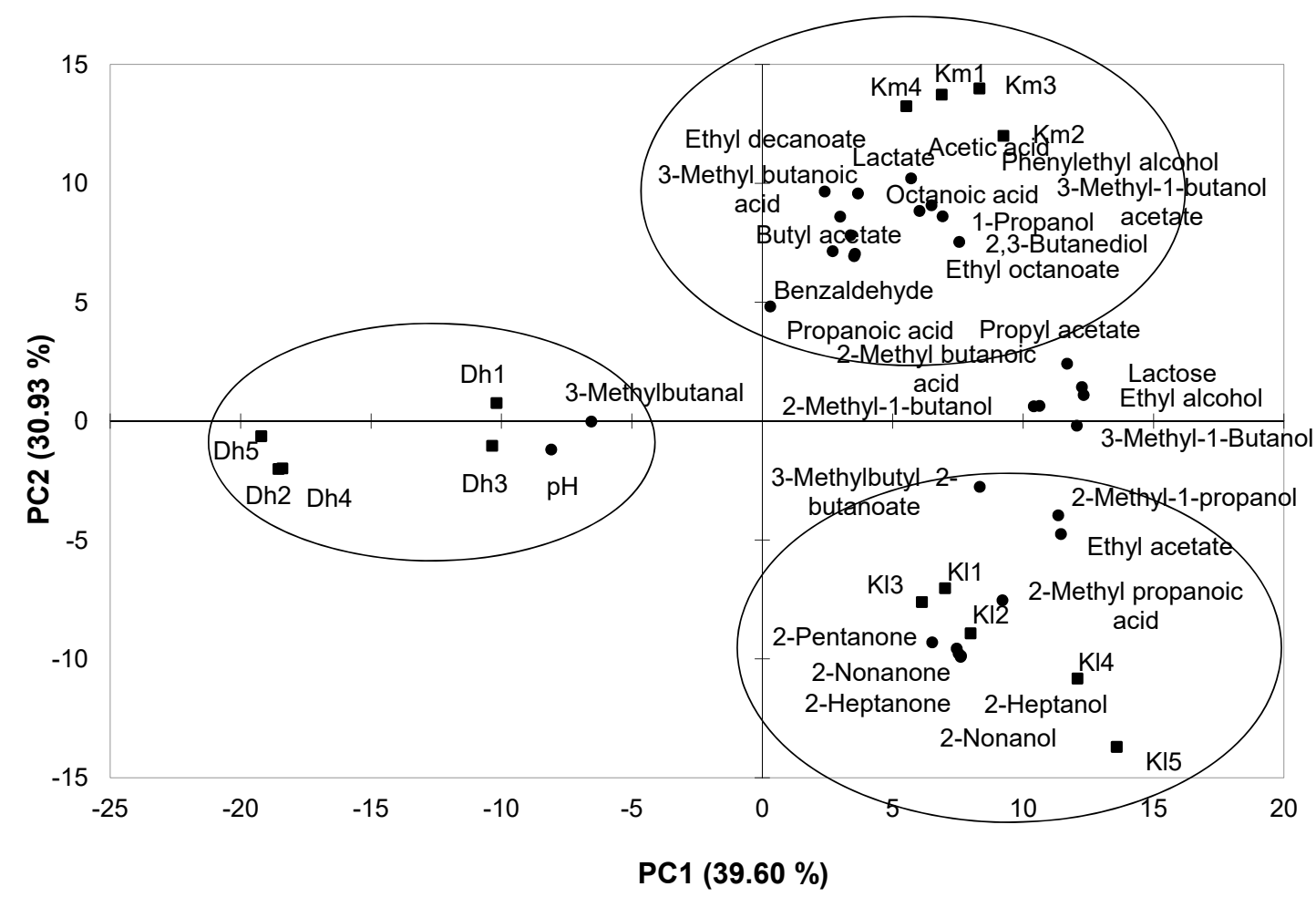


